\title{
NEUROTRIBES: THE LEGACY OF AUTISM AND FUTURE OF NEURODIVERSITY (BOOK REVIEW)
}

\author{
Badr Ratnakaran \\ Resident in Psychiatry, Dept. of Psychiatry and Behavioural Sciences, Virginia Tech Carilion School of Medicine, Roanoke, \\ Virginia, USA. \\ Correspondence: 2017, South Jefferson Street, Roanoke, Virginia, USA-24014. Email: dr.badrratnakaran@gmail.com
}

Title: Neurotribes: The Legacy of Autism and Future of Neurodiversity

Author: Steve Silberman

Publisher: Avery Publishing

Pages: 542

Year: 2015

We, as doctors, are many a times enamored by the stalwarts in the field of medicine. Hippocrates, William Osler, Sigmund Freud, Watson and Crick, etc. are names well known to us from our early years as medical students. Their contributions have shaped our knowledge, and some of us aspire to leave a mark in the field of medicine just like them.

However, our textbooks mostly mention their names and contributions only in a sentence or two. We do not know who they are as a person, their stories, their struggles, and what led them to their discoveries and achievements. This includes how the practice of medicine shaped and evolved in time with their contributions. Siddhartha Mukherjee's 2011 Pulitzer Prize-winning The Emperor of All Maladies: A Biography of Cancer is one such book which narrates the history of cancer from accounts about it in Egyptian and Greek civilizations to current advancements in its research and treatment. Randy Shilt's 1987 book And the Band Played on: Politics, People and the AIDS Epidemic chronicles how the Human Immunodeficiency Virus and subsequently the Acquired Immune Deficiency Syndrome were discovered. It tells the story of struggles of the patients and the medical fraternity who had to face not only the stigma when it was initially conceived as a "gay disease" but also the apathy from the government and ego clashes between scientists researching the disease. Stories like these are not told in textbooks, and books like the ones mentioned above provide a humanistic view to the field of medicine.

There are numerous books on such narratives in the field of mental illness. The late Dr Oliver Sacks' works have always been popular and captivate the imagination of the general public with his accounts of fascinating presentations of neurological and psychiatric disorders. They have always left a lasting impression on us in understanding the overlap between the science of these two branches of medicine. Ultimately, these accounts underline how fascinating our brain is.

The book in review, Neurotribes: The Legacy of Autism and the Future of Neurodiversity is written by Steve Silberman. Silberman is a journalist for the WIRED magazine, which focuses on technology and how it shapes the world around us. Neurotribes 
is a New York Times bestseller and in 2015 had won the Samuel Johnson award, a prominent literary prize for nonfiction books. Before the release of this book, Silberman had been well known for his article on the impact of placebo effect on research in the pharmaceutical industry. ${ }^{1}$

The catalyst for Silberman's book was his article "The Geek Syndrome", where he discusses the increasing number of children in the Silicon Valley, California, USA, being diagnosed with autism. ${ }^{2}$ The book's first chapter also starts from here on Silberman's encounters with many experts from science and technology. He notices their unique behavioral traits — from their fastidious fascination to science along with their innovative skills, social awkwardness, and intolerance to sensory cues like the alarm from a washing machine which a normal person will find tolerable or trivial. He finds that many of these traits are many a times found in a much severe form in the children of such people. This leads them to be diagnosed with autism. Thus starts Silberman's inquiry into the beginnings of the concept of autism and tracing its evolution through time to our present world.

With his gripping narrative through twelve chapters, Silberman touches upon various themes related to autism. It starts with his wonderful account on Lord Henry Cavendish, the famous scientist from the $18^{\text {th }}$ century whose many pioneering works include the discovery of hydrogen. Silberman describes a day in the life of Lord Cavendish riddled by his preference of social isolation. His daily life consisted of numerous rituals and routines with a penchant for accuracy and precision in research. He was a man of knowledge and his acumen was considered in the highest regard by the elite British Royal Society, a learned society of prominent scientists in the world. This reviewer feels that the following excerpt from the book beautifully captures the essence of Lord Cavendish's behavior and how his colleagues would deal with him:
"It is not true, however, that he wanted to remove himself entirely from the company of his peers; he just wanted to stand off to the side, soaking everything in. Two scientists conversing on a topic of interest at the Royal Society's Monday Club might notice a hunched figure in a grey-green coat lurking in the shadows, listening intently. Eager to solicit his appraisal of their work, his fellow natural philosophers devised a devious but effective method of drawing him into an exchange.

"The way to talk to Cavendish is never to look at him," said astronomer Francis Wollaston, "but to talk as it were, into a vacancy, and then it is not unlikely, but you may set him going." Once he was set going, it turned out that he had plenty to say. "If he speaks to you, continue the conversation," Wollaston advised."

Similar to the above excerpt, Silberman, through anecdotes, describes the lives of various prominent personalities who belonged to the autism spectrum (AS), including scientists Temple Grandin and Nobel Prize-winning physicist Paul Dirac. We understand the evolution of the concept of autism from "schizophrenic reaction, childhood type" in the first edition of Diagnostic and Statistical Manual of Mental Disorders (DSM) in 1952 to its current acknowledgement of it as a spectrum of symptoms as AS disorders in the current edition of DSM. He describes the influence of popular media on autism, including the movie Rain Man's (1988) influence on spreading awareness on autism when it had been a relatively unknown entity, and the fascination for science fiction by those belonging to the AS.

Through harrowing accounts of families and their children belonging to the AS, we are taken to periods where the prevailing treatments in psychiatry were based on psychoanalysis and behavior therapy. Many of the treatment strategies were based on damaging theories and treatment of autism including refrigerator mothers, holding therapy, parentectomy and acceptance of punishment as a therapy for stereotypical behaviors 
displayed by autistic children. We understand the genesis of the controversy behind the association of MMR vaccine and autism and the propagation of orthomolecular treatment for autism which had no scientific basis. In the process, we are introduced to the rise and fall of George Wakefield, Bruno Bettleheim and Bernard Rimland, who were once considered experts on autism based on the abovementioned concepts but later became discredited and thus their fall from grace. They were humans who started their journeys in efforts to help autistic children and their parents but fell to the follies of their egos and narrow-mindedness to accept their mistakes or deviation from their views.

But, the book's highlight lies in its biographical accounts of two names synonymous with autism, Hans Asperger and Leo Kanner. Silberman, by describing Hans Asperger's story, takes us to Vienna under the Nazi regime. Silberman narrates the political atmosphere of the Nazi regime at the time and their eugenic policies. Fearing that children with disabilities might be persecuted due to these policies, Hans Asperger might have selectively highlighted only savants belonging to the AS. With this effort, he might have tried to convince the Nazi regime that people belonging to the AS might be highly skilful and important for the society, thus trying to save autistic children of all forms of severity. We learn about Leo Kanner's humble beginnings and his rise as the highest authority on autism during his time. But Silberman also describes Kanner's inflexible vision of autistic children being severely disabled and his belief that the disease has a very low prevalence. He was unwilling to accept that many of the criteria set by him in diagnosing autism had overlapping characteristics with other conditions, including childhood schizophrenia and schizoid personality disorder. Kanner was also a staunch supporter of psychoanalytic theories of autism, including toxic parenting and refrigerator mothers. Thus, Silberman portrays Hans Asperger as a saintly figure, a hero; and Leo Kanner as a villain whose stubborn ego to change from his views might have thwarted the recognition of children belonging to the less severe spectrum of autism. Silberman also hypothesizes that Leo Kanner, who knew German, should have been aware of Hans Asperger's works on autism. Especially since Kanner had worked with the Jewish psychologist George Frankl who had also worked with Hans Asperger before fleeing the Nazi regime. George Frankl, though not popularly credited, had been the common denominating factor in both Kanner's and Asperger's works on autism as their chief diagnostician.

Coming to our present world, we see how technology like social media brings together people with autism and their caregivers. Using online fora and arranging social gatherings, they fight for their rights, make friends, and help cope with each other. In the process, they find their niche and a space of acceptance.

In the end, Silberman persuades us to see disorders like AS disorders, specific learning disorders, attention deficit hyperactivity disorder, etc. as diverse presentations of normal human behavior (or "neurotribes" as mentioned by him). They should be seen as variants of cognitive difference and not a pathology. We should work towards providing measures in helping them to integrate with our society rather than trying to fix them to our expectancy of being normal human beings. This is the core idea behind the neurodiversity movement coined by Judy Singer in $1999 .{ }^{3}$ In short, it is we who have to change to adapt to their needs rather than expecting them to be cured and be like us. In Silberman's words: "Just because a computer is not running Windows doesn't mean that it's broken. Not all the features of atypical human operating systems are bugs."

Silberman's humanistic and investigative approach to autism makes his work akin to an epic saga which is evident by the 500 plus pages of the book. It is a long read. The language is simple and devoid of too many medical jargons which very much helps the 
common man to understand the content and holds their attention. Throughout the narration of the book, we are introduced to various characters and historical events of the past century that have influenced our perspectives on mental illness, including autism. The author goes at great lengths to describe them, providing the reader a vivid picture of the practice of medicine, especially psychiatry, during different eras along with the political and socioeconomic climate during those times, including World War II. This helps the reader to understand why autism was viewed and dealt in a different manner during different time periods. However, this reviewer felt that the long descriptions are many a times a deviation or a distraction from the main points Silberman tries to highlight in his narrative.

Silberman's focus of his message is more based on his experiences: American culture, moderate to severe end of the AS, those who belong to the middle and higher socioeconomic status and have access to resources for help. This might not be generalised to the severe end of the autistic spectrum and to countries like India which are still behind in awareness among the general population and accessibility to resources. ${ }^{4}$

The book, in the end, is a valuable and entertaining read, especially for trainees in psychiatry and other fields related to mental health. They could learn that, beyond our tomes describing medicine and therapy, there are stories that have shaped what we practise today that can inspire us to do much more. Ultimately, we have to strive to be advocates for our patients and try our best not to fall for our biases to our views on mental illness. There is much work to be done in spite of our efforts so far.

\section{REFERENCES}

1. Silberman S. Placebos are getting more effective. Drugmakers are desperate to know why [monograph on the Internet]. Wired; 2009 [cited 2018 Jan 26]. Available from: https://www.wired.com/2009/08/ff-placeboeffect/
2. Silberma S. The geek syndrome [monograph on the Internet].Wired; 2001[cited 2018 Jan 26]. Available from: https://www.wired.com/2001/12/aspergers /

3. Jaarsma $\mathrm{P}, \mathrm{W}$ elin $\mathrm{S}$. Autism as a natural human variation: Reflections on the claims of the neurodiversity movement. Health Care Anal 2012; 20:20-30.

4. Desai MU, Divan G, Wertz FJ, Patel V. The discovery of autism: Indian parents' experiences of caring for their child with an autism spectrum disorder. Transcult Psychiatry 2012; 4:613-37.

Source of support: None

Conflict of interest: None declared

First submitted: $26^{\text {th }}$ January 2018

Published online: $26^{\text {th }}$ February 2018 